\title{
An empirical model to estimate ultraviolet erythemal transmissivity
}

\author{
M. Antón, A. Serrano, M. L. Cancillo, and J. A. García \\ Departamento de Física, Universidad de Extremadura, 06071 Badajoz, Spain \\ Received: 16 July 2008 - Revised: 24 December 2008 - Accepted: 27 February 2009 - Published: 1 April 2009
}

\begin{abstract}
An empirical model to estimate the solar ultraviolet erythemal irradiance (UVER) for all-weather conditions is presented. This model proposes a power expression with the UV transmissivity as a dependent variable, and the slant ozone column and the clearness index as independent variables. The UVER were measured at three stations in South-Western Spain during a five year period (2001-2005). A dataset corresponding to the period 2001-2004 was used to develop the model and an independent dataset (year 2005) for validation purposes. For all three locations, the empirical model explains more than $95 \%$ of UV transmissivity variability due to changes in the two independent variables. In addition, the coefficients of the models show that when the slant ozone amount decreases $1 \%$, UV transmissivity and, therefore, UVER values increase approximately $1.33 \%-1.35 \%$. The coefficients also show that when the clearness index decreases $1 \%$, UV transmissivity increase $0.75 \%-0.78 \%$. The validation of the model provided satisfactory results, with low mean absolute bias error (MABE), about $7 \%-8 \%$ for all stations. Finally, a one-day ahead forecast of the UV Index for cloud-free cases is presented, assuming the persistence in the total ozone column. The percentage of days with differences between forecast and experimental UVI lower than \pm 0.5 unit and \pm 1 unit is within the range of $28 \%$ to $37 \%$, and $60 \%$ to $75 \%$, respectively. Therefore, the empirical model proposed in this work provides reliable forecast cloud-free UVI in order to inform the public about the possible harmful effects of UV radiation over-exposure.
\end{abstract}

Keywords. Atmospheric composition and structure (Transmission and scattering of radiation)

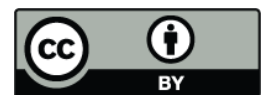

Correspondence to: M. Antón (mananton@unex.es)

\section{Introduction}

In the last years, the study of solar ultraviolet (UV) radiation has received considerable attention in mid-latitudes because of the intensive radiation reaching the earth's surface at these latitudes due to the depletion of the stratospheric ozone. Although UV radiation represents a small part of the solar spectrum, it presents notable positive and negative effects over the human health. Small amounts of solar ultraviolet radiation are beneficial for people and essential in the production of vitamin D3 (Webb and Holick, 1988). Conversely, an overexposure to the solar UV radiation may result in detrimental effects on the skin, eyes and immune systems of humans. According to the study by Lopez-Abente et al. (1996), during the period 1978-1992, the melanoma (the most dangerous type of skin cancer) annually rose about $5 \%$ in Spain. The World Health Organisation (WHO) has estimated in up to $20 \%$ the number of cases of cataracts related to overexposure to ultraviolet radiation (WHO, 1995). Moreover, the UV radiation presents a large influence over many biological, ecological and photochemical processes, being quite harmful for living organisms. In particular, UV radiation increase can cause adverse effects on plant growth, photosynthesis and aquatic ecosystems (the major contributor to the earth's biomass) (Diffey, 1991). Therefore, nowadays, regional, national and international organizations promote the installation of UV measuring networks in order to monitor the UV solar radiation reaching the earth's surface.

Regarding the harmful effects on biological systems, UVB $(280-315 \mathrm{~nm})$ is the most detrimental ultraviolet band, although its contribution to total UV irradiance is less than $10 \%$. Recently, the erythema or sunburn in human's skin is the harmful effect that has received most attention. Thus, this effect is commonly quantified weighing the solar UV radiation with the erythemal spectral response, resulting in the so called ultraviolet erythemal radiation (UVER). The curve adopted in 1987 by the Commission Internationale de l'Eclairage (CIE) (McKinlay and Diffey, 1987) is currently

Published by Copernicus Publications on behalf of the European Geosciences Union. 
recommended as the standard erythemal action spectrum. Therefore, the variable UVER is recognized internationally as a standard for determining the risk associated to UV radiation. In the last years, the UV Index (UVI) has been introduced as an useful vehicle to inform the public about the potentially harmful effects of the UV radiation and it is directly calculated using the variable UVER (WMO, 1998).

Long-term ground-based datasets have been utilized for detecting trends in UVER and for establishing its climatology (WMO, 2003, and references therein). In addition, radiative transfer and empirical methods are useful tools for estimating UVER where there are no measurements available. Radiative transfer models describe the physical interaction between UV radiation and the atmosphere. These models offer better accuracy in calculated UV irradiances than empirical models, but they need information about meteorological variables which are not commonly measured in groundbased stations. In contrast, empirical models are formulated by simple expressions with the available meteorological variables in each location as independent variables. This type of estimation methods have been broadly used for different goals such as: UVI forecast (Borrows et al., 1994; Krzyscin et al., 2001; Foyo-Moreno et al., 2007; Madronich, 2007), estimation of total ozone column (Fioletov et al., 1997; Kerr and Davis, 2007), and reconstruction of UV radiation series (Gantner et al., 2000; Fioletov et al., 2002; Lindfors and Vuilleumier, 2005; Eerme et al., 2006).

The independent variables introduced in the empirical model have to characterize the modulation of UV radiation through the atmosphere. In this direction, the most important factors influencing UV radiation reaching ground level are the elevation solar, total ozone column, clouds and aerosols. Due to the complexity of the interaction between UV radiation and the atmosphere, a great number of UV empirical models focus on the relationship between UV and a single factor such as: global solar radiation (Feister and Grasnick, 1992; Martínez-Lozano et al., 1999; Ramírez et al., 2003; Robaa, 2004; den Outer et al., 2005), ozone (McKenzie et al., 1991; Madronich, 1992; Bais et al., 1993) and the optical air mass (Foyo-Moreno et al., 1999; Dubrovsky, 2000; Cañada et al., 2000; Murillo et al., 2003). In contrast, few studies analyze the joint relationship between the UV radiation and its main attenuation factors (Diaz et al., 2000; Fioletov et al., 2001; Krzyscin et al., 2001; de La Casinière et al., 2002; Foyo-Moreno et al., 2007).

The objective of this work is to propose an empirical model for all-sky conditions in order to estimate the UVER variable at three stations in South-Western Spain using two independent variables which characterize the main atmospheric attenuation factors of the UV radiation. In addition, this article analyzes the use of the proposed empirical model for reporting UV Index.

Category labels associated with numerical interval of the UVI are a practice tool to inform people about the erythemal risk. Despite this risk, it depends on the type of skin, COST-
713 Action "Long term changes and climatology of UV radiation over Europe" established a universal category with intervals ranging from low erythemal risk ( $0-3)$, moderate (4-6), high (7-9) and extreme (>10) (Vanicek et al., 2000). For latitudes corresponding to Iberian Peninsula, UVI equal to 10 is an exceptionally high value recorded several times per year (Martínez-Lozano, 2002). Therefore, the study presented in this work is of relevant interest in the Iberian Peninsula, and particularly in its South-Western area due to the high UV radiation recorded at these latitudes throughout the year (Serrano et al., 2006).

The instrumentation and the data used in this paper are described in Sect. 2. Section 3 describes the methodology followed by the proposal of the empirical model. Section 4 presents and discusses the results obtained in this work and, finally, Sect. 5 summarizes the main conclusions.

\section{Data}

Total solar irradiance and UVER data have been measured at three stations located in Badajoz $\left(38.99^{\circ} \mathrm{N}, 7.01^{\circ} \mathrm{W}\right.$, altitude $=199 \mathrm{~m}$ a.s.1.), Cáceres $\left(39.48^{\circ} \mathrm{N}, 6.34^{\circ} \mathrm{W}, 397 \mathrm{~m}\right.$ a.s.1. $)$ and Plasencia $\left(40.06^{\circ} \mathrm{N}, 6.04^{\circ} \mathrm{W}, 372 \mathrm{~m}\right.$ a.s.l.). These stations are located in Extremadura region (Southwest of the Iberian Peninsula) (Fig. 1), which presents a climate type of Csa according to the Köppen Climate Classification (Mediterranean mild climate with hot summers and mild rainy winters). According to the climatic values given by INM (2004), Badajoz presents an annual average of total precipitation of $477.51 / \mathrm{m}^{2}$ with maximum monthly values in March $\left(67.91 / \mathrm{m}^{2}\right)$ and minimum in July $\left(2.91 / \mathrm{m}^{2}\right)$. Monthly mean temperature varies in this location from $8.7^{\circ} \mathrm{C}$ in January to $25.9^{\circ} \mathrm{C}$ in July, and the sunshine duration between June and August is higher than $1000 \mathrm{~h}$ in average, which emphasizes the interest in monitoring UV solar radiation in this region.

The three radiometric stations have been installed and maintained by the AIRE (Fisica de la Atmósfera, clIma y Radiación en Extremadura) research group of the University of Extremadura. Total solar irradiance $(310-2800 \mathrm{~nm})$ and UVER data were measured on a plane and horizontal surface, using a UV-S-E-T broadband pyranometer and a CM$6 \mathrm{~B}$ pyranometer, respectively. Both instruments are manufactured by Kipp \& Zonen - Scintec (Delft, The Netherlands). Radiative measurements were sampled every ten seconds and recorded as one-minute mean voltages on Campbell CR10X data acquisition systems. The output voltages provided by UV-S-E-T instrument were converted into UVER values by means of the calibration factors obtained in outdoor inter-calibration campaigns using a well-characterized Brewer MK-III spectrophotometer as reference. More details about the calibration of the UV broadband radiometers can be found in the paper by Cancillo et al. (2005). 


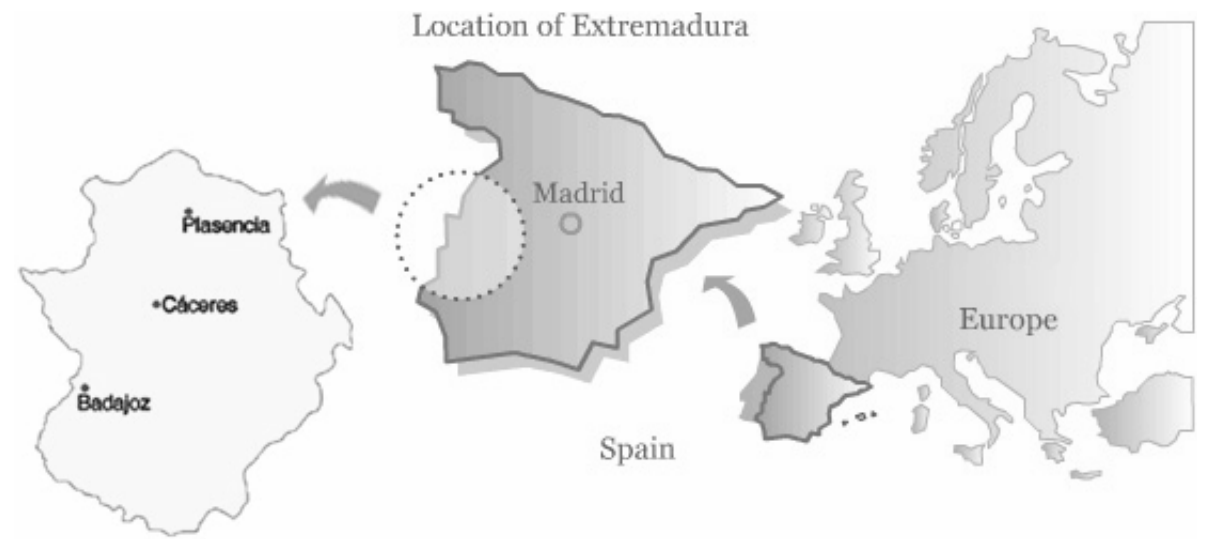

Fig. 1. Location of the three stations belonging to the broadband radiometer network, managed by AIRE reseach group, in the Southwest of the Iberian Peninsula.

All radiative data used in this article are obtained as the daily average around solar noon (between 11:00 and 13:00 h).

Additionally, the total ozone column (TOC) data from remote sensing Total Ozone Mapping Spectrometer (TOMS) instrument were used. The TOMS remote sensor has been operative on board two satellites: Nimbus-7 (1978-1993) and Earth Probe (EP) (1996-2005). This satellite instrument measures the backward-scattered Earth solar radiance in six 1-nm bands in the UV-A and UV-B spectral regions and the extraterrestrial solar radiance in the same six wavelength channels. This information is used to estimate spatial distributed daily values of TOC expressed in Dobson Units (DU) with a horizontal spatial resolution of TOMS ozone data of $1^{\circ}$ latitude $\times 1.25^{\circ}$ longitude. In general, there is a very good agreement between the TOMS ozone estimations and ground based measurements (Fioletov et al., 2002; Masserot et al., 2002). In addition, McPeters et al. (1998) reported that the TOC provided by TOMS is only about $1 \%$ higher than the ground measurements in 30 mid-northern latitude stations.

\section{Methodology}

In this section, the variables used in the all-weather empirical model are described in detail. This empirical model estimates the UV transmissivity (dependent variable), using two input variables (independent variables): the slant ozone and the clearness index. In addition, the steps in the proposal of the empirical model are explained. Finally, the data used in this work are also examined.

\subsection{Model variables}

\subsubsection{UV transmissivity}

UV erythemal transmissivity is used as a dependent variable in the empirical model proposed in this paper. This variable is defined by the following expression:

$T_{\mathrm{UV}}=\frac{E_{\mathrm{UV}}}{E_{\mathrm{UV}}^{\mathrm{TOA}}}$,

where $E_{\mathrm{UV}}$ is the UVER measured at the surface by broadband radiometers and $E_{\mathrm{UV}}^{\mathrm{TOA}}$ is the UVER at the top of the atmosphere (extraterrestrial UVER). The calculation of this extraterrestrial UV erythemal irradiance is based on a set of algorithms that depend on the day of the year and the latitude of the location under study:

$E_{\mathrm{UV}}^{\mathrm{TOA}}=S_{\mathrm{UV}}\left(\frac{r_{0}}{r}\right)^{2} \cos \theta$

considering the spectral solar values given by Frohlich and Wherli (Iqbal, 1983), the erythemal solar constant $\left(\mathrm{S}_{U V}\right)$ for the UV interval $(280-400 \mathrm{~nm})$ weighed by the standard CIE spectral response results in $10.3 \mathrm{~W} \mathrm{~m}^{-2}$. Moreover, $\left(\frac{r_{0}}{r}\right)^{2}$ is the eccentricity correction factor defined as the square of the ratio of mean Earth-Sun distance $\left(r_{0}\right)$ to the distance at a given time $(r)$, and $\theta$ is the solar zenith angle.

The selection of the ratio UVER at the earth's surface to extraterrestrial UVER has the great advantage that its changes can be exclusively attributed to atmospheric attenuation factors. Therefore, the proposed empirical model using the UV transmissivity as a dependent variable is more general than if the untransformed variable was used.

\subsubsection{Clearness index}

The clearness index is chosen for characterizing jointly the cloud cover and aerosol load. This variable has been broadly 
used for this objective (Foyo-Moreno et al., 1999; Cañada et al., 2000; Ogunjobi et al., 2004) and it is calculated as:

$k_{t}=\frac{E_{G}}{E_{G}^{\mathrm{TOA}}}$,

where $E_{G}$ is the total solar irradiance measured at groundbased over a horizontal surface, and $E_{G}^{\mathrm{TOA}}$ is the extraterrestrial total solar irradiance on a horizontal surface. This irradiance is calculated by the expression (2), with a solar constant for the whole solar spectrum of $1367 \mathrm{~W} \mathrm{~m}^{-2}$.

The variable $k_{t}$ characterizes the absorption and scattering processes of total solar irradiance. Both attenuation processes are mainly due to clouds and aerosol load. Thus, the clearness index variations can be attributed to those two attenuation factors.

When sky conditions considerably change during the averaging time, the use of the instantaneous cloud observations for analyzing the cloud effects on UV irradiance may yield confusing results (Calbó et al., 2005). This problem disappears when using the clearness index, because both variables (UV irradiance and clearness index) are averaged over the same time interval.

The elevate number of cloud-free days during summer in the Extremadura region produces the monthly values of the clearness index that present higher values in this season than in the rest of the year. In this sense, the monthly mean $k_{t}$ values ( \pm one standard deviation) vary between $0.55 \pm 0.18$ (October) and $0.74 \pm 0.08$ (July) for Badajoz, between $0.52 \pm 0.19$ (October) and $0.75 \pm 0.07$ (July) for Cáceres, and between $0.47 \pm 0.23$ (October) and $0.73 \pm 0.10$ (July) for Plasencia. In addition, the standard deviation of the monthly mean $k_{t}$ values shows that the variability of the clearness index in summer is lower than the variability in the other seasons.

\subsubsection{Slant ozone column}

The actual ozone amount crossed through by the solar radiation in the atmosphere is the slant ozone column defined as:

$Z=\frac{\mathrm{TOC}}{\mu}$,

where $\mu$ is the cosine of the solar zenith angle. This expression is only valid for the direct solar irradiance. However, it can be used as a good approximation for the global solar irradiance (direct+diffuse) since the largest part of ozone absorption occurs at high altitudes, before the scattering processes by aerosols and clouds.

TOC values are obtained by TOMS satellite instrument which was described in Sect. 2. Since this work focuses on the UVER measured in the period $+/-$ one hour around solar noon (between 11:00 and 13:00 UTC), a single daily TOMS ozone overpass between 10:30 and 11:30 UTC could be taken as the representative value for the whole 2-h period around solar noon.

\subsection{Proposal of the empirical model}

The relationship between the attenuated $\left(I_{\lambda}\right)$ and the extraterrestrial $\left(I_{0 \lambda}\right)$ normal beam spectral irradiance can be expressed as:

$I_{\lambda}=I_{0 \lambda} \cdot \tau_{\lambda}$,

where $\tau_{\lambda}$ represents the spectral atmospheric transmittance when all atmospheric attenuating factors are considered.

Assuming the hypothesis of additivity in the atmospheric processes, the spectral transmittance may be expressed as (Iqbal, 1983):

$\tau_{\lambda}=\prod_{i=1}^{n} \tau_{\lambda i}$

where $\tau_{\lambda i}$ corresponds to the spectral transmittance for the atmospheric attenuating factor $i$.

The main objective of this article is to develop an empirical model based on the relationship between the UV erythemal irradiance and its main attenuating factors. Thus, assuming that the two main UV attenuation factors, ozone and clouds, are independent of each other, the empirical model may be obtained by rewriting the spectral transmittance expression (Eq. 6) for UVER measurements:

$T_{\mathrm{UV}}=T_{Z} \cdot T_{k_{t}}$,

where $T_{\mathrm{UV}}$ is the total UV flux transmissivity (defined by Eq. 1), and $T_{Z}$ and $T_{k t}$ are the UV flux transmissivity due exclusively to ozone and to clouds and aerosols, respectively. Similar parametric expressions have been previously proposed for broadband solar measurements, for example, the models A, B and C proposed by Iqbal (1983).

In the work by Antón (2007) the individual relationships between the UV transmistivity and the main attenuating atmospheric factors (total ozone column, clearness index and relative optical mass) is analyzed using different empirical expressions (polynomial, exponential and power law). The results indicated that the power-low model is the more adequate, fitting in order to relate the UV transmissivity to the main atmospheric attenuating factors. Thus, the Eq. (7) can be written as:

$T_{\mathrm{UV}}=a \cdot Z^{b} \cdot k_{t}^{c}$,

where $a, b$ and $c$ are the coefficients of the model, and $k_{t}$ and $Z$ are the independent variables defined by expressions (3) and (4), respectively. The coefficients $b$ and $c$ give information about the influence of the changes of the slant ozone column and clearness index to the variability in UV transmissivity.

\subsection{Selection of data}

The period analyzed in this work ranges between January 2001 and December 2005, guaranteeing that a wide range of 


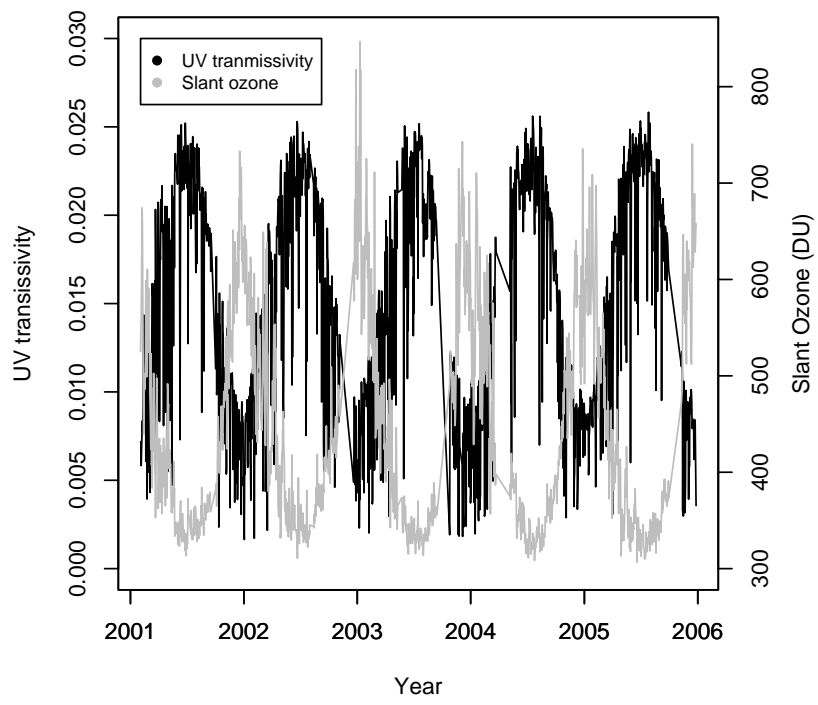

Fig. 2. The daily mean evolution of UV transmissivity and slant ozone column for the period 2001-2005 at Badajoz station.

TOC, sky conditions and solar elevation angles are included in this study.

All data used in this article are obtained as the daily average around solar noon (between 11:00 and 13:00 h). At mean latitudes, this restriction retains only low solar zenith angles. Thus, the variables used in this paper: UV transmissivity, clearness index and slant ozone column are calculated for solar zenith angles lower than $65^{\circ}$.

In order to obtain the coefficients of the empirical model, one data set was selected, corresponding to the period between January 2001 and December 2004. Thus, this data set had 1220 data for Badajoz, 1027 for Cáceres and 794 for Plasencia. The rest of the data recorded during the year 2005 were used for the validation of the model. For this goal, the number of data in each location was: 312 (Badajoz), 321 (Cáceres) and 313 (Plasencia).

\section{Results and discussion}

\subsection{Model estimation}

Ozone, clouds and aerosols are the most important factors to be considered in order to estimate the UV transmissivity. Figure 2 shows the daily mean values for $T_{\mathrm{UV}}$ and $Z$ during the whole period of study for the Badajoz station. It can be seen as an opposite seasonal behaviour of two variables. The low values of the slant ozone column during summer produces high UV transmissivity values in this season. The opposite pattern is observed during the winter. In addition, the Cáceres and Plasencia stations showed a very similar behaviour. The marked annual cycle of slant ozone column is mainly caused by variations in the length of the optical path due to changes on the solar elevation. However, the monthly

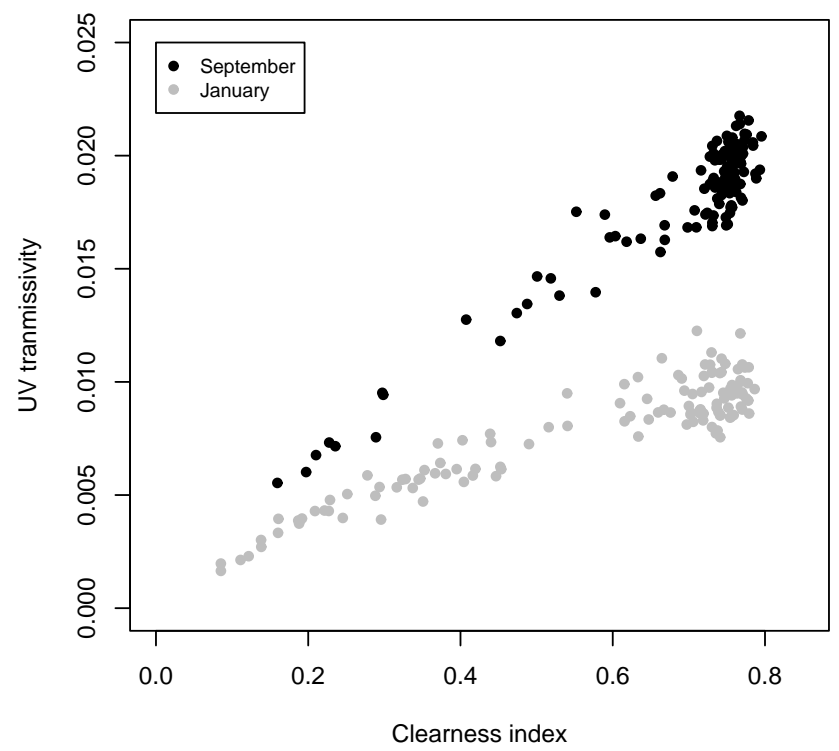

Fig. 3. UV transmissivity versus the clearness index for two representative months corresponding to winter (January) and late summer (September) at Badajoz station.

variability of the slant ozone column is mainly controlled by changes on the total ozone column which presents a higher variability during winter and early spring at middle latitudes (Antón et al., 2008a). This fact is mainly due to the synoptic weather systems at middle and high latitudes that notably affect the fluctuations in lower stratosphere ozone during this period (Vaughan and Price, 1991).

On the other hand, the temporal evolution of the UV transmissivity sometimes shows notable day-to-day changes attributed mainly to cloudiness, since the slant ozone column presents small day-to-day fluctuations. In order to check the influence of the clearness index changes on UV transmissivity, Fig. 3 shows the relationship between both variables for two representative months corresponding to winter (January) and late summer (September) in the Badajoz station. September was selected since June, July and August lack enough cloudy days for the study. The case studies were 124 in January and 120 in September. It can be observed that a strong, positive correlation between the clearness index and the variable $T_{\mathrm{UV}}$. Thus, when $k_{t}$ is low (high cloudiness and/or high aerosol load) the variable $T_{\mathrm{UV}}$ is also low and vice versa. In addition, the figure shows that the UV transmissivity is lower in January than September. This fact is mainly due to the slant ozone column, crossed by UVER, is higher in winter than in summer.

A multiple regression analysis was performed in order to calculate the coefficients of the model (Eq. 8), using the least squares approach. Table 1 shows the results obtained for the three locations including the coefficient of determination $R^{2}$ (fraction of experimental data variance explained by the model) and the root mean square error (RMSE). These results 
Table 1. Results of the multiple regression analysis for Badajoz, Cáceres and Plasencia.

\begin{tabular}{lccccc}
\hline & $a$ & $b$ & $c$ & $R^{2}$ & RMSE \\
\hline Badajoz & $70 \pm 4$ & $-1.33 \pm 0.01$ & $0.78 \pm 0.01$ & 0.98 & 0.0012 \\
Cáceres & $70 \pm 5$ & $-1.35 \pm 0.01$ & $0.76 \pm 0.01$ & 0.98 & 0.0012 \\
Plasencia & $63 \pm 9$ & $-1.33 \pm 0.02$ & $0.75 \pm 0.01$ & 0.95 & 0.0018 \\
\hline
\end{tabular}

suggest that more than $95 \%$ of the UV transmissivity may be accounted for by changes in the slant ozone column and the clearness index at the three locations. The coefficients $b$ and $c$ are useful indicators of the sensitivity of UV transmissivity and, therefore, UVER values, to changes of ozone and cloudiness+aerosols, respectively.

The parameter $b$ has been proposed as a new radiation amplification factor (RAF) for the UV erythemal irradiance (Serrano et al., 2008). The high value of the parameter $b$, obtained in the three locations, indicates that UV transmissivity is highly sensitive to changes in the slant ozone column. Thus, if there is a decrease of $1 \%$ in the slant ozone column between two days with the same clearness index, then UV transmissivity increases between $1.33 \%$ and $1.35 \%$ in the three locations. In addition, the fact that the coefficient $c$ is quite lower (in absolute terms) than coefficient $b$ shows that UV transmissivity and, therefore, UVER values, are more sensitive to changes in the slant ozone column than in cloudiness. Thus, if the clearness index rises $1 \%$ between two days with identical slant ozone column, then UV transmissivity only increases about $0.78 \%, 0.76 \%$ and $0.75 \%$ in Badajoz, Cáceres and Plasencia, respectively. It is important to note that the mentioned higher sensitivity of UVER transmissivity to changes in slant ozone column than in cloudiness does not necessarily mean that the variation of UVER transmissivity is mostly explained by changes in slant ozone. UVER variability will also depend on the magnitude of the change in slant ozone and cloudiness, and these depend highly on the case and the temporal scale considered.

The multiple regression analysis between the UV transmissivity and the variables slant ozone column and clearness index is performed for each month of the year in order to analyse the seasonal variation of the coefficients $b$ and $c$. These coefficients are shown in Table 2, ranged by months for Badajoz, Cáceres and Plasencia. It is observable that for the months between May and September, the cloudiness influence over UV transmissivity is more significant than the influence of the slant ozone column. This fact may be attributed to the lower slant ozone variability during late spring and summer due to the low variability in the total ozone column during these months.
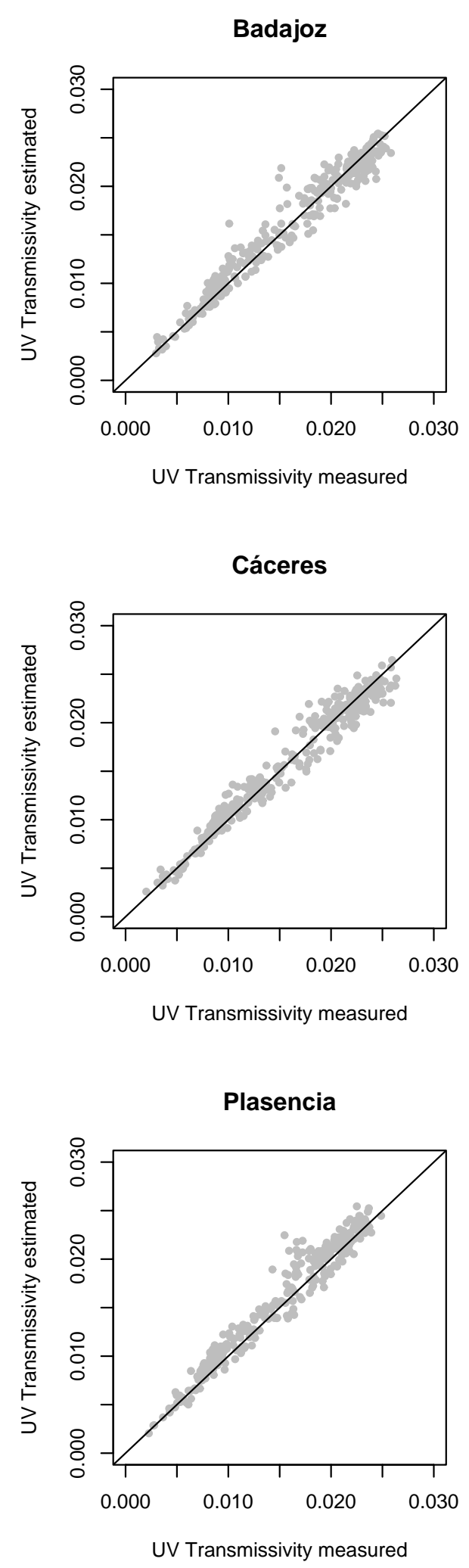

Fig. 4. Relationship between the experimental and estimated UV transmissivity at Badajoz, Cáceres and Plasencia stations. 


\subsection{Validation of the model}

The model has been validated with the remaining data which were not used for the calculation of the fitting parameters. Thus, an independent database was selected for each location in order to validate the proposed model. A linear regression analysis between measured and estimated values of UV transmissivity has been performed for every station. Table 3 shows the results obtained for every regression analysis including the coefficient of determination $R^{2}$, the slope and the intercept $a$ of the regression line. It can be seen that values $R^{2}$ are higher than 0.95 and the slopes are nearly similar for the three locations. These results reveal the validity of the proposed model. Moreover, in order to analyze the relative differences between the experimental and estimated values, the statistical relative parameters MBE (Mean Bias Error) and MABE (Mean Absolute Bias Error) were calculated, as follows:

$\mathrm{MBE}=100 \times \frac{1}{N} \sum_{i=1}^{N} \frac{T_{\mathrm{UV}_{i}}^{\bmod }-T_{\mathrm{UV}_{i}}^{\exp }}{T_{\mathrm{UV}_{i}}^{\exp }}$,

$\mathrm{MABE}=100 \times \frac{1}{N} \sum_{i=1}^{N} \frac{\left|T_{\mathrm{UV}_{i}}^{\bmod }-T_{\mathrm{UV}_{i}}^{\exp }\right|}{T_{\mathrm{UV}_{i}}^{\exp }}$,

The parameter MABE reports about the absolute value of the relative differences between experimental data and model estimations. Table 3 shows the values of this parameter obtained for the three locations, indicating that the model proposed in this work estimates the UV transmissivity with a mean error between $7 \%$ and $8 \%$. In addition, the positive value of the MBE for the three stations shows that the proposed model overestimates in average the experimental values. This overestimation is $2.8 \%$ for Badajoz, $1.9 \%$ for Cáceres and $5.8 \%$ for Plasencia. Thus, absorbing aerosols can substantially reduce UVER and have a much smaller effect on the total solar irradiance (Antón et al., 2008b) and, therefore, over the clearness index variability. In this perspective, forest fires could be the major source of absorbing aerosols in Extremadura during the summer.

The higher MBE value for Plasencia could be related to local factors which have not been considered in the model, such as its more complex orography and its lower number of cloud-free cases compared to the other two stations.

The comparison between experimental data and model estimations is also performed for each month of the year in 2005. The parameters MBE and MABE are shown in Table 4 for the three locations. There is a period without measurements during October 2005 since the three broadband UV radiometers participated in one calibration campaign in El Arenosillo station. It is observable that the parameter MBE presents lower values between March and July. Thus, the model underestimates the experimental values during AprilJune in Badajoz, during April-July in Cáceres and, during
April in Plasencia. In contrast, the months of November, December and January present the higher values of the parameter MBE and MABE. These results could be related to the differences found between the coefficients $b$ and $c$ for each month (Table 2) and some coefficients for the whole period (Table 1).

Figure 4 shows the correlation between experimental and modelled UV transmissivity values for the three stations of the study. It can be seen that most points are located near the line $1: 1$, indicating a good agreement between experimental and modelled values. A more detailed inspection of Fig. 4 reveals that the deviation between measured and estimated values is not uniform across the range of UV transmissivity values, mainly at Badajoz and Cáceres. Thus, this figure shows that the proposed model underestimates the largest experimental UV transmissivity values at Badajoz and Cáceres. In this direction, if the relative differences between experimental and estimated values are calculated for the cases with experimental UV transmissivity values higher than 0.02 , the parameters $\mathrm{MBE}$ are $-2.0 \%$ for Badajoz and $-2.2 \%$ for Cáceres. For Plasencia, the overestimation is substantially reduced reaching the parameters $\mathrm{MBE}$ a value of $+2.7 \%$.

\subsection{UV Index forecast}

The UV Index (UVI) has been recommended by several international organizations such as: World Meteorological Organization (WMO), World Health Organization (WHO), United Nations Environment Programme (UNEP) and International Commission on Non-lonizing Radiation Protection (ICNIRP), as a useful vehicle to inform the public about the magnitude of the UVER at the earth's surface in order to protect themselves against the potentially harmful effects of the UV radiation. The UVI is calculated by multiplying the UVER irradiance (expressed in $\mathrm{W} / \mathrm{m}^{2}$ ) by 40 according to the joint recommendation of the WMO, WHO, UNEP and ICNIRP meeting on UV-B radiation and UV forecast in July 1997 (WMO, 1998).

The empirical model proposed in this work allows us to estimate UVER values and, thus the UV Index for all weather conditions. In this subsection, the UVI forecast using the empirical model is analyzed. This application has a great interest since it is necessary to know the UVI in advance for informing people about the possible risks of solar radiation over-exposure.

The UVI forecast is calculated for cloud-free conditions since this prediction has to correspond to the daily maximum value in order to alert the public. Thus, a constant clearness index equal to 0.913 (Badajoz), 0.927 (Cáceres) and 0.901 (Plasencia) is introduced in the empirical model. This value corresponds to the percentile 99 of all clearness index values measured during the period of study for each location.

Since the forecasted ozone field is not available in real time for our locations, a persistence hypothesis has been assumed in this work (the next day's TOC equals it preceding day's 
Table 2. Coefficients $b$ and $c$ of the multiple regression analysis for Badajoz, Cáceres and Plasencia corresponding to each calender month.

\begin{tabular}{lcccccc}
\hline & \multicolumn{2}{c}{ Badajoz } & \multicolumn{2}{c}{ Cáceres } & \multicolumn{2}{c}{ Plasencia } \\
& $b$ & $c$ & $b$ & $c$ & $b$ & $c$ \\
\hline January & $-0.77 \pm 0.05$ & $0.75 \pm 0.01$ & $-0.89 \pm 0.06$ & $0.71 \pm 0.01$ & $-0.57 \pm 0.11$ & $0.76 \pm 0.02$ \\
February & $-0.86 \pm 0.05$ & $0.79 \pm 0.01$ & $-1.11 \pm 0.06$ & $0.77 \pm 0.01$ & $-0.52 \pm 0.15$ & $0.81 \pm 0.03$ \\
March & $-0.89 \pm 0.04$ & $0.80 \pm 0.01$ & $-1.05 \pm 0.08$ & $0.80 \pm 0.02$ & $-0.96 \pm 0.02$ & $0.83 \pm 0.03$ \\
April & $-0.86 \pm 0.05$ & $0.83 \pm 0.01$ & $-0.97 \pm 0.04$ & $0.82 \pm 0.01$ & $-1.18 \pm 0.18$ & $0.77 \pm 0.04$ \\
May & $-0.77 \pm 0.05$ & $0.86 \pm 0.01$ & $-0.89 \pm 0.05$ & $0.89 \pm 0.01$ & $-1.11 \pm 0.21$ & $0.67 \pm 0.04$ \\
June & $-0.59 \pm 0.08$ & $0.86 \pm 0.02$ & $-0.69 \pm 0.08$ & $0.88 \pm 0.02$ & $-0.70 \pm 0.13$ & $0.87 \pm 0.03$ \\
July & $-0.13 \pm 0.11$ & $0.92 \pm 0.03$ & $-0.26 \pm 0.13$ & $0.96 \pm 0.05$ & $-0.51 \pm 0.10$ & $0.90 \pm 0.02$ \\
August & $-0.54 \pm 0.11$ & $0.81 \pm 0.02$ & $-0.34 \pm 0.14$ & $0.85 \pm 0.02$ & $-1.15 \pm 0.17$ & $0.85 \pm 0.02$ \\
September & $-0.74 \pm 0.11$ & $0.79 \pm 0.02$ & $-0.55 \pm 0.10$ & $0.82 \pm 0.02$ & $-0.61 \pm 0.11$ & $0.78 \pm 0.02$ \\
October & $-1.01 \pm 0.09$ & $0.79 \pm 0.01$ & $-1.01 \pm 0.08$ & $0.82 \pm 0.01$ & $-1.03 \pm 0.12$ & $0.72 \pm 0.02$ \\
November & $-0.80 \pm 0.07$ & $0.74 \pm 0.01$ & $-0.89 \pm 0.07$ & $0.68 \pm 0.01$ & $-1.31 \pm 0.17$ & $0.70 \pm 0.03$ \\
December & $-0.56 \pm 0.07$ & $0.73 \pm 0.01$ & $-0.74 \pm 0.08$ & $0.72 \pm 0.01$ & $-0.80 \pm 0.17$ & $0.77 \pm 0.01$ \\
\hline
\end{tabular}

Table 3. Results of the validation analysis for Badajoz, Cáceres and Plasencia.

\begin{tabular}{lccccc}
\hline & $a$ & Slope & $R^{2}$ & MBE $(\%)$ & MABE (\%) \\
\hline Badajoz & $0.0014 \pm 0.0002$ & $0.924 \pm 0.011$ & 0.95 & +2.80 & 7.75 \\
Cáceres & $0.0011 \pm 0.0002$ & $0.935 \pm 0.010$ & 0.96 & +1.88 & 7.10 \\
Plasencia & $0.0014 \pm 0.0002$ & $0.924 \pm 0.011$ & 0.95 & +5.79 & 8.27 \\
\hline
\end{tabular}

value). This hypothesis is based on the small day-to-day variations of the ozone layer in mid-latitudes, mainly during summer when the UV Index predictions are more useful. In order to test the persistence hypothesis, the relative one day change in TOC is calculated by the following expression:

$(\Delta \mathrm{TOC})_{i}=100 \times \frac{\left(\mathrm{TOC}_{i+1}-\mathrm{TOC}_{i}\right)}{\mathrm{TOC}_{i}}$,

where $\mathrm{TOC}_{i}$ and $\mathrm{TOC}_{i+1}$ are the total ozone column for two consecutive days. The absolute mean value of $\triangle \mathrm{TOC}$ for all cases is $4.8 \%$ (Badajoz), $5.0 \%$ (Cáceres) and $5.1 \%$ (Plasencia), showing the small day-to-day changes in TOC values. If the relative one day change is calculated only for the cases measured between June and September, its absolute mean values decrease to $2.9 \%$ (Badajoz), $3.1 \%$ (Cáceres) and $3.0 \%$ (Plasencia). Therefore, the persistence hypothesis in TOC is valid during summer when the highest UVI values are recorded.

The slant ozone column introduced in the forecast model was calculated using the persistence hypothesis in TOC and the solar zenith angle corresponding to solar local noon. Thus, the lowest daily slant ozone column is used in the model for forecasting maximum daily UVI values.

To validate how well these indices are predicted, it is necessary to compare them with experimental values. The observed daily UVI is obtained as the daily maximum taken from a set of $5 \mathrm{~min}$ averages of the UVER values reaching the earth's surface. The data measured during the year 2005 were used for this UVI validation study. Days classified by Cost-713 Action (Vanicek et al., 2000) as cases with high erythemal risk (UVI between 7 and 9 calculated as an integer number) correspond to $45.3 \%$ (Badajoz), $45.0 \%$ (Cáceres) and $45.2 \%$ (Plasencia) of all cases. Moreover, days with extreme erythemal risk (UVI equal or higher than 10) occur in $3.8 \%$ (Badajoz), and $4.4 \%$ (Cáceres) of cases. These results show the interest of reporting reliable UV Index values in South-Western Spain.

Figure 5 shows the relationship between UVI forecast and observations for each location. Both indexes have been obtained as physical variables, i.e. decimal UVI values have been used. It can be seen that in most cases, forecasted UVI is higher than the experimental UVI (underestimation of UV Index occurs only in $10 \%-13 \%$ of all cases). Thus, the proposed model provides highly reliable values for UVI. For cloud-free cases $\left(k_{t}>0.75\right)$, the dispersion shown in this figure is notably reduced. Thus, this dispersion may be mainly attributed to cloudy days since UVI is predicted for cloudfree cases. When the absolute differences between experimental and modeled values are calculated, results show that the UVI is almost exactly correct ( \pm 0.5 index unit) in $37.0 \%$ of the days for Badajoz, 35.8\% for Cáceres and $28.4 \%$ for Plasencia. In addition, about $75 \%$ of all the cases for Badajoz and Cáceres and about $60 \%$ for Plasencia, the forecasted 
Table 4. Parameters MBE and MABE of the model validation for Badajoz, Cáceres and Plasencia corresponding to each calender month.

\begin{tabular}{lcccccc}
\hline & \multicolumn{2}{c}{ Badajoz } & \multicolumn{2}{c}{ Cáceres } & \multicolumn{2}{c}{ Plasencia } \\
& MBE $(\%)$ & MABE $(\%)$ & MBE (\%) & MABE (\%) & MBE (\%) & MABE (\%) \\
\hline January & 13.55 & 13.62 & 9.81 & 10.56 & 13.95 & 13.95 \\
February & 5.15 & 7.78 & 4.48 & 6.27 & 5.98 & 8.19 \\
March & 0.64 & 6.22 & 0.60 & 6.26 & 2.31 & 5.72 \\
April & -3.30 & 8.47 & -5.09 & 9.15 & -2.27 & 6.89 \\
May & -2.95 & 6.26 & -2.80 & 6.42 & 0.47 & 4.79 \\
June & -4.47 & 6.25 & -4.83 & 5.70 & 3.08 & 4.37 \\
July & 1.07 & 4.71 & -0.54 & 3.97 & 5.68 & 6.76 \\
August & 6.88 & 8.45 & 5.04 & 6.38 & 10.44 & 10.56 \\
September & 4.28 & 5.41 & 4.54 & 5.07 & 8.32 & 9.31 \\
October & - & - & - & - & - & - \\
November & 6.60 & 9.02 & 8.28 & 10.17 & 9.01 & 10.38 \\
December & 5.39 & 9.69 & 5.04 & 10.23 & 8.57 & 11.84 \\
\hline
\end{tabular}

Table 5. Percentiles 10, 50 and 90 of the absolute differences between the UVI forecast and the experimental values for each class of erythemal risk: low (UVI experimental lower than 3), moderate (between 4 and 6), high (between 7 and 9) and extreme (equal or higher than $10)$.

\begin{tabular}{lcccc}
\hline & Low & Moderate & High & Extreme \\
\hline Badajoz & $0.24,0.57,1.15$ & $0.15,0.80,2.77$ & $0.21,0.75,1.67$ & $0.21,0.40,0.88$ \\
Cáceres & $0.29,0.58,0.97$ & $0.22,0.80,1.80$ & $0.12,0.72,1.58$ & $0.09,0.26,0.90$ \\
Plasencia & $0.17,0.57,1.20$ & $0.23,0.94,2.53$ & $0.24,1.09,1.72$ &,,--- \\
\hline
\end{tabular}

UVI is within \pm 1.0 index unit. In order to analyse the model performance for various classes of the experimental UV Index, Table 5 shows the percentiles 10, 50 (median) and 90 of the absolute differences between the UV Index forecasted and the experimental values for each class of erythemal risk: low (UVI experimental lower than 3), moderate (between 4 and 6), high (between 7 and 9) and extreme (equal or higher than 10). It is observable that the median value of the absolute differences is lower than the similar four classes except in the high class in Plasencia. This station does not present any UV Index value in the extreme class due to the factors appointed in Sect. 4.2. The elevated value of the differences in the percentile 90 is mainly due to cloudy days since the predictions are obtained for cloud-free conditions. It should be noted that the UV forecast using the proposed empirical model provide excellent results when these predictions are compared with experimental values.

\section{Conclusions}

This work focuses on the proposal of an empirical model in order to estimate the UV erythemal irradiance at three locations in Extremadura (South-Western Spain). This model proposes a power-low relationship between the UV atmo- spheric transmissivity (dependent variable) and two independent variables; the slant ozone column and the clearness index, which characterizes the main attenuation factors of the UV radiation. For the three locations, the proposed model explain more than $95 \%$ of UV transmissivity variance due to changes in those two independent variables. In addition, the coefficients of the empirical model introduced in this paper show that UV transmissivity is more sensitive to the variation in the slant ozone column than in the clearness index (mainly due to fluctuations of the cloud cover and the aerosol load). Thus, changes of $1 \%$ in slant ozone column and clearness index would produce a variation in UV transmissivity of $1.33 \%-1.35 \%$ and $0.75 \%-0.78 \%$, respectively.

The model was validated using a dataset different to the employed one in the calculation of the coefficients. The absolute values of the relative differences between the estimated and measured data were about $8 \%$ for the three locations. This result indicates that the empirical expression proposed in this article notably reproduces the experimental UVER values.

Finally, the ability of the empirical model to forecast the UV Index was analyzed. This UVI prediction is obtained for cloud-free cases considering persistence in the total ozone column. It is found that the percentage of cases with differences in UVI lower than 0.5 is in the range of $28 \%$ to $37 \%$, 

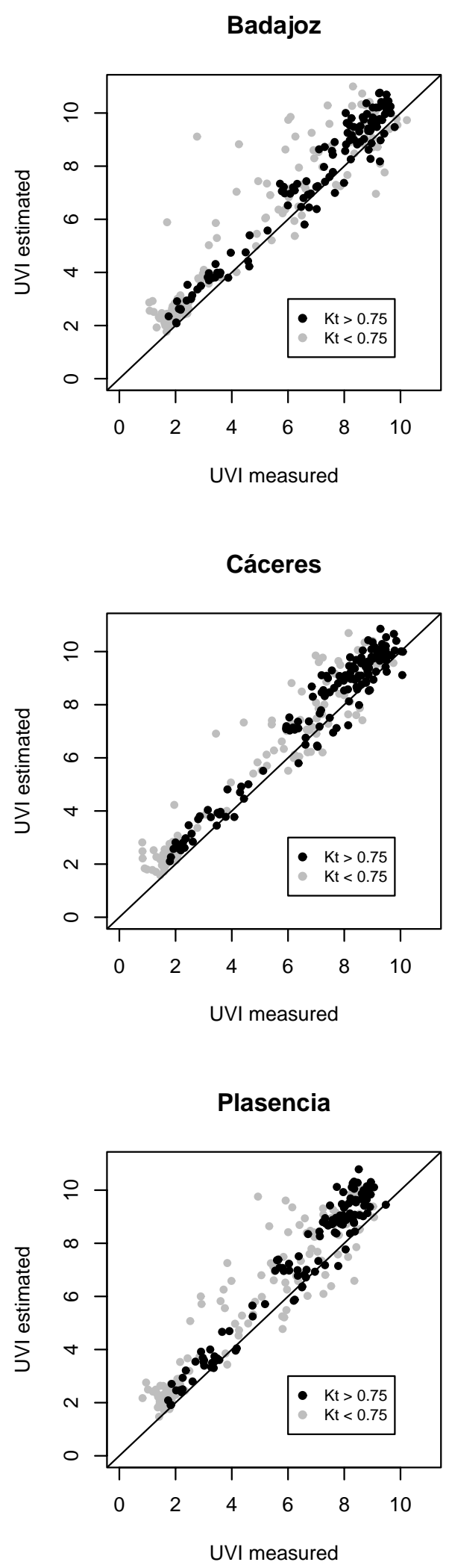

Fig. 5. Relationship between the experimental and predicted UV Index at Badajoz, Cáceres and Plasencia stations. while the percentage of the cases with differences in UVI lower than one covers the range $60 \%$ to $75 \%$. Therefore, the prediction for cloud-free cases of the UV Index with the empirical model proposed in this work is acceptable.

Acknowledgements. This work has been supported by Ministerio de Educación y Ciencia under project CGL2005-05693-C03-03/CLI, by Ministerio de Ciencia e Innovación under project CGL200805939-C03-02/CLI, by the Junta de Extremadura under "Convenio para la creación y mantenimiento de una red de medida de la radiación solar ultravioleta en Extremadura", and under the project GRU07126.

Topical Editor F. D'Andrea thanks two anonymous referees for their help in evaluating this paper.

\section{References}

Antón, M.: Modelos empíricos para la estimación de la irradiancia solar ultravioleta, PhD Thesis, University of Extremadura, 2007.

Antón, M., Serrano, A., Cancillo, M. L., and García, J. A.: Total ozone and solar erythemal irradiance in South-Western Spain: day-to-day variability and extreme episodes, Geophys. Res. Lett., 35, L20804, doi:10.1029/2008GL035290, 2008a.

Antón, M., Serrano, A., Cancillo, M. L., and García, J. A.: Relationship between erythemal irradiance and total solar irradiance in South-Western Spain, J. Geophys. Res., 113, D14208, doi:10.1029/2007JD009627, 2008b.

Bais, A., Zerefos, C., Meleti, C., Ziomas, I., and Tourpali, K.: Spectral measurements of solar UVB radiation and its relations to total ozone, SO, and clouds, J. Geophys. Res., 98, 5199-5204, 1993.

Burrows, W., Valle, M., Wardle, D., Kerr, J., Wison, L., and Tarasick, D.: The Canadian operational procedure for forecasting total ozone and UV radiation, Meteorol. Appl., 1, 247-265, 1994.

Calbó, J., Pagés, D., and González, J.: Empirical studies of cloud effects on UV radiation: a review, Rev. Geophys., 43, RG2002, doi:10.1029/2004RG000155, 2005.

Cancillo, M. L., Serrano, A., Antón, M., García, J. A., Vilaplana, J. M., and de la Morena, B.: An improved outdoor calibration procedure for broadband ultraviolet radiometers, Photochem. Photobiol., 81, 860-865, 2005.

Cañada, J., Pedrós, G., López, A., and Boscá, J.: Influences of the clearness index for the whole spectrum and of the relative optical air mass on UV solar irradiance for two locations in the Mediterranean area, Valencia and Córdoba, J. Geophys. Res., 105, 4799_ 4766, 2000.

de La Casinière, A., Toure, M., Masserot, D., Cabot, T., and Pinedo, J. L.: Daily doses of biologically active UV radiation retrieved from commonly available parameters, Photochem. Photobiol., 76, 171-175, 2002.

Den Outer, P. N., Slaper, H., and Tax, R. B.: UV radiation in the Netherlands: Assessing long-term variability and trends in relation to ozone and clouds, J. Geophys. Res., 110, D02203, doi:10.1029/2004JD004824, 2005.

Diaz, S., Deferrari, G., Martinioni, D., and Olberto, A.: Regression analysis of biologically effective integrated irradiances versus ozone, cloud and geometric factors, J. Atmos. Sol. Terr. Phys., 62, 629-638, 2000. 
Diffey, B. L.: Solar ultraviolet radiation effects on biological systems, Phys. Med. Biol., 36, 299-328, 1991.

Dubrovsky, M.: Analysis of UV-B irradiances measured simultaneously at two stations in the Czech Republic. J. Geophys. Res., 105, 4907-4913, 2000.

Eerme, K., Veismann, U., and Lätt, S.: Proxy-based reconstruction of erythemal UV doses over Estonia for 1955-2004, Ann. Geophys., 24, 1767-1782, 2006, http://www.ann-geophys.net/24/1767/2006/.

Feister, U. and Grasnick, K. H.: Solar UV radiation measurements at Postdam (52 $\left.22^{\prime} \mathrm{N}, 13^{\circ} 5^{\prime} \mathrm{E}\right)$, Sol. Energy, 49, 431-544, 1992.

Fioletov, V. E., Kerr, J., and Wardle, D.: The relationship between total ozone and spectral UV irradiance from Brewer observations and its use for derivation of total ozone from UV measurements, Geophys. Res. Lett., 24, 2997-3000, 1997.

Fioletov, V. E., McArthur, L., Kerr, J. E., and Wardle, D. I.: Longterm variations of UV-B irradiance over Canada estimated from Brewer observations and derived from ozone and pyranometer measurements, J. Geophys. Res., 106, 2309-2307, 2001.

Fioletov, V. E., Kerr, J. B., Wardle, D. I., Krotkov, N. I., and Herman, J. R.: Comparison of Brewer ultraviolet irradiance measurements with total ozone mapping spectrometer satellite retrievals, Opt. Eng., 41, 3051-3061, 2002.

Foyo-Moreno, I., Vida, J., and Alados-Arboledas, L.: A simple all weather model to estimate ultraviolet solar radiation (290385 nm), J. Appl. Meteorol., 38, 1020-1026, 1999.

Foyo-Moreno, I., Alados, I., and Alados-Arboledas, L.: Adaptation of an empirical model for erythemal ultraviolet irradiance, Ann. Geophys., 25, 1499-1508, 2007, http://www.ann-geophys.net/25/1499/2007/.

Gantner, L., Winkler, P., and Kohler, U.: A method to derive longterm time series and trends of UV-B radiation (1968-1997) from observations at Hohenpeissenberg (Bavaria), J. Geophys. Res., 27, 4879-4888, 2000.

Iqbal, M.: An Introduction to Solar Radiation. Academic Press Canada, 1983.

INM: Guía resumida del clima en España 1971-2000, Instituto Nacional de Meteorología, Ministerio de Medio Ambiente, Madrid, 2004.

Kerr, J. B. and Davis, J. M.: New methodology applied to deriving total ozone and other atmospheric variables from global irradiance spectra, J. Geophys. Res., 112, D21301, doi:10.1029/2007JD008708, 2007.

Kryscin, J. W., Jaroslawski, J., and Sobolewski, P.: On an improvement of UV index forecast: UV index diagnosis and forecast for Belsk, Poland, in Spring/Summer 1999, J. Atmos. Sol. Terr. Phys., 63, 1593-1600, 2001.

Lindfors, A. and Vuilleumier, L.: Erythemal UV at Davos (Switzerland), 1926-2003, estimated using total ozone, sunshine duration, and snow depth, J. Geophys. Res., 110, D02104, doi:10.1029/2004JD005231, 2005.

Lopez-Abente, G., Pollán, M., Escolar, A,, Errezola, M., and Abraira, V.: Atlas of cancer mortality and other causes of death in Spain 1978-1992, Fundación Científica de la Asociación Española Contra el Cáncer Madrid, 1996, available at: http: //www2.uca.es/hospital/atlas92/www/Atlas92.html, accessed 2 June 2007.

Madronich, S.: Implications of recent total atmospheric ozone measurements for biologically active ultraviolet radiation reaching the earth surface, Geophys. Res. Lett., 19, 37-40, 1992.

Madronich, S.: Analytic Formula for the Clear-sky UV Index, Photochem. Photobiol., 83, 1537-1538, 2007.

Martínez-Lozano, J. A., Tena, F., and Utrillas, M. P.: Ratio of UV to Global broad band irradiation in Valencia, Spain, Int. J. Climatol., 19, 903-911, 1999.

Martínez-Lozano, J. A., Marín, M. J., Tena, F., Utrillas, M. P., Sánchez-Muniosguren, L., González, L., Cuevas, E., Redondas, A., Lorente, J., de Cabo, X., Cachorro, V. E., Vergaz, R., de Frutos, A., Díaz, J., Expósito, F., de la Morena, B., and Vilaplana, J. M.: UV Index experimental values during the years 2000 and 2001 from the Spanish broadband UVB radiometric network, Photochem. Photobiol., 76, 181-187, 2002.

Masserot, D., Lenoble, J., Brogniez, C., Houet, M., Krotkov, N., and McPeters, R.: Retrieval of ozone column from global irradiance measurements and comparison with TOMS data. A year of data in the Alps, Geophys. Res. Lett., 29, 1309, doi:10.1029/2002GL014823, 2002.

McKenzie, R., Matthews, W., and Johnston, P.: The relationship between erythemal UV and Ozone derived from spectral irradiance measurements, Geophys. Res. Lett., 18, 2269-2272, 1991.

McKinlay, A. F. and Diffey, B. L.: A reference spectrum for ultraviolet induced erythema in human skin, CIE Journal, 6, 21-27, 1987.

McPeters, R. D., Bhartia, P. K., Krueger, A. J., Herman, J. R., Wellemeyer, C. G., Seflor, C. F., Jaross, G., Torres, O., Moy, L., Labow, G., Byerly, W., Taylor, S. L., Swisler, T., and Cebula, R. P.: Earth Probe Total Ozone Mapping Spectrometer (TOMS) Data products User Guide, Technical report TP-1998-206895, NASA, 1998.

Murillo, W., Cañada, J., and Pedrós, G.: Correlation between global ultraviolet (290-385 $\mathrm{nm}$ ) and global irradiation in Valencia and Córdoba (Spain), Renew. Energy, 28, 409-418, 2003.

Ogunjobi, K. O. and Kim, Y. J.: Ultraviolet $(0.280-0.400 \mu \mathrm{m})$ and broadband solar hourly radiation at Kwangju, South Korea: analysis of their correlation with aerosol optical depth and clearness index, Atmos. Res., 71, 193-214, 2004.

Ramírez, L., Polo, J., Mora, L., Sidrach, M., and Blanco, J.: Fuzzy inference system applied to the daily ultraviolet radiation evaluation (295-385 nm) from daily global radiation, Sol. Energy, 75, 447-454, 2003.

Robaa, S. M.: A study of ultraviolet solar radiation at the Cairo urban area, Egypt, Sol. Energy, 77, 251-259, 2004.

Serrano, A., Antón, M., Cancillo, M. L., and Mateos, V. L.: Daily and annual variations of erythemal ultraviolet radiation in Southwestern Spain, Ann. Geophys., 24, 427-441, 2006, http://www.ann-geophys.net/24/427/2006/.

Serrano, A., Antón, M., Cancillo, M. L., and García, J. A.: Proposal of a new erythemal UV radiation amplification factor, Atmos. Chem. Phys. Discuss., 8, 1089-1111, 2008, http://www.atmos-chem-phys-discuss.net/8/1089/2008/.

Vaughan, G. and Price, J.: On the relation between total ozone and meteorology, Q. J. Roy. Meteor. Soc., 117, 1281-1298, 1991.

Vanicek, K., Frei, T., Lytinska, Z., and Schnalwieser, A.: UV-Index for the public. Report of the COST-713 Action, European Commission, 2000.

Webb, A. and Holick, M.: The role of sunlight in the cutaneous production of vitamin D3, Annu. Rev. Nutr., 8, 375-399, 19998.

WHO, World Health Organization: Protection against exposure to 
ultraviolet radiation, Technical Report WHO/EHG 17, 1995.

WMO, World Meteorological Organization: Report of the WMOWHO meeting of experts on standardization of UV indices and their dissemination to the public, Technical Report 127, WMO/Global Atmosphere Watch, 1998.

WMO, World Meteorological Organization: Scientific assessment of ozone depletion: 2002, global ozone research and monitoring project, Technical Report 47, 2003.
Wohltmann, I., Rex, M., Brunner, D., and Mader, J.: Integrated equivalent latitude as a proxy for dynamical changes in ozone column, Geophys. Res. Lett., 32, L09811, doi:10.1029/2005GL022497, 2005. 